\title{
Übertragung nosokomialer Infektionen und Prinzipien der Transmissionsprävention
}

\section{Roland Schulze-Röbbecke}

\author{
Nur die genaue Kenntnis des tatsächlichen Übertragungswegs von (nosokomialen) Infektions- \\ krankheiten ermöglicht es, die richtigen Schutzmaßnahmen zur Prävention zu treffen und eine \\ wirksame Expositionsprophylaxe zu erreichen.
}

\section{Einleitung}

Die Übertragung von Infektionskrankheiten erfolgt bekanntlich auf unterschiedlichen Wegen. So werden z.B. Salmonellen und Noroviren durch orale Aufnahme in den Gastrointestinaltrakt übertragen, Hepatitis-CVirus (HCV) und humanes Immundefizienz-Virus (HIV) parenteral und durch Schleimhautkontakt, Keuchhustenerreger durch Aufnahme respiratorischer Tröpfchen in die oberen Atemwege und Dermatophyten durch Hautkontakt.

Bedeutung für die Expositionsprophylaxe. Kenntnisse über die spezifischen Übertragungswege der verschiedenen Infektionskrankheiten sind von grundlegender Bedeutung für die Infektionsprävention, denn die meisten Infektionen lassen sich weder durch Immunprophylaxe (aktive oder passive Immunisierung) noch durch Chemoprophylaxe (prophylaktische Gabe von Antiinfektiva) verhindern. Gegen alle diese Infektionen, die auch unter den nosokomialen Infektionen bei Weitem überwiegen, steht nur die Expositionsprophylaxe zur Verfügung, d.h. die Verhinderung der Erregerexposition oder des infektiologisch effektiven Erregerkontakts.

\section{Der Übertragungsweg entscheidet über die Wahl der} Schutzmaßnahme. Die Expositionsprophylaxe verfügt über mannigfaltige Instrumente. Diese reichen von der Identifizierung und Elimination von Infektionsquellen (z.B. Erkennung und Therapie von Geschlechtskrankheiten oder Tuberkulose) über verschiedene Formen der räumlichen Absonderung (z.B. Kontaktisolierung, Tröpfchenisolierung, häusliche Quarantäne), technische Maßnahmen wie Sterilisation, Desinfektion und Raumlufttechnik bis hin zu mechanischen Barrieren wie Moskitonetzen und Kondomen sowie persönlicher Schutzausrüstung (PSA, hierzu zählen z. B. Augenschutz, Mund-Nasen-Schutz, Atemschutzmasken, Schutzhandschuhe und Schutzkleidung).

Die richtige Anwendung expositionsprophylaktischer Maßnahmen ist von fundamentaler Bedeutung für den Patientenschutz, den Arbeitsschutz und die öffentliche Gesundheit.

Um expositionsprophylaktische Maßnahmen effektiv und ökonomisch einsetzen zu können, sind Kenntnisse über die spezifischen Übertragungswege der verschiedenen Infektionskrankheiten unabdingbar.

Beispiele. Im Bereich der Patientenversorgung ist z. B. die Händedesinfektion eine äußerst kosteneffektive Maßnahme zur Prävention der Übertragung multi- 
resistenter Erreger; bei der Prävention der nosokomialen Übertragung von HCV, HIV und Tuberkulose spielt sie dagegen kaum eine Rolle. Die HCV- und HIV-Übertragung lässt sich durch Vermeidung von Stichverletzungen sowie durch Einsatz von mechanischen Barrieren wie Schutzhandschuhen, Mund-Nasen-Schutz und Schutzbrille verhindern, während zur Prävention der Tuberkuloseübertragung schwebstofffiltrierende (FFP-) Atemschutzmasken und aufwendige raumlufttechnische Maßnahmen von Bedeutung sind. Umgekehrt gibt es keine wissenschaftliche Grundlage für die Annahme, dass sich die Übertragung multiresistenter Erreger wie Methicillin-resistenter Staphylococcus aureus (MRSA) durch Schleusen vor Patientenzimmern oder Raumlufttechnik beeinflussen lässt.

Viele, wenn nicht die meisten nosokomialen Infektionen (z.B. Beatmungspneumonien, postoperative Wundinfektionen und Infektionen durch MRSA) sind

\section{Tabelle 1}

Direkte Übertragungsmechanismen (nach [4]).

\begin{tabular}{|c|c|c|}
\hline Bezeichnung & Erläuterung & Beispiele \\
\hline \multirow[t]{2}{*}{$\begin{array}{l}\text { direkte Kontakt- } \\
\text { übertragung }\end{array}$} & $\begin{array}{l}\text { unmittelbare, sofortige Erre- } \\
\text { gerübertragung von einem } \\
\text { infizierten/kolonisierten Men- } \\
\text { schen in empfängliche Ein- } \\
\text { trittspforte eines anderen } \\
\text { Menschen mit Folge einer } \\
\text { Infektion }\end{array}$ & $\begin{array}{l}\text { unmittelbarer Hautkontakt } \\
\text { zwischen zwei Personen; Küs- } \\
\text { sen (z. B. Epstein-Barr-Virus); } \\
\text { Geschlechtsverkehr }\end{array}$ \\
\hline & $\begin{array}{l}\text { Sonderform Tröpfchenüber- } \\
\text { tragung: Erregerhaltige } \\
\text { Spritzer oder Tröpfchen von } \\
\text { Körperflüssigkeiten (Blut, } \\
\text { Sekrete, Ausscheidungen) } \\
\text { eines infizierten/kolonisier- } \\
\text { ten Menschen gelangen auf } \\
\text { Konjunktiven oder Mund- } \\
\text { Nasen-Rachen-Schleimhaut } \\
\text { eines anderen Menschen. } \\
\text { Die Übertragung ist norma- } \\
\text { lerweise auf eine Distanz } \\
\text { von } 1 \text { m begrenzt. }\end{array}$ & $\begin{array}{l}\text { Person A hustet Person B ins } \\
\text { Gesicht; Spritzer von Erbro- } \\
\text { chenem von Person A gelan- } \\
\text { gen ins Gesicht von Person } \\
\text { B; Blut eines Patienten } \\
\text { spritzt in das ungeschützte } \\
\text { Auge eines Chirurgen. }\end{array}$ \\
\hline $\begin{array}{l}\text { direkte Erreger- } \\
\text { exposition }\end{array}$ & $\begin{array}{l}\text { unmittelbare Exposition von } \\
\text { empfänglichem mensch- } \\
\text { lichem Gewebe gegenüber } \\
\text { Erregern, deren natürliches } \\
\text { Habitat sich in der Umwelt } \\
\text { befindet }\end{array}$ & $\begin{array}{l}\text { systemische Mykose durch } \\
\text { Kontakt mit verrottendem } \\
\text { Material, in dem der Erreger } \\
\text { als Saprophyt lebt }\end{array}$ \\
\hline $\begin{array}{l}\text { diaplazentare } \\
\text { Übertragung }\end{array}$ & $\begin{array}{l}\text { Übertragung während der } \\
\text { Schwangerschaft von der } \\
\text { Mutter auf das ungeborene } \\
\text { Kind }\end{array}$ & $\begin{array}{l}\text { konnatale Röteln, } \\
\text { konnatale Toxoplasmose }\end{array}$ \\
\hline
\end{tabular}

endogenen Ursprungs, d.h. sie werden nicht zwischen Menschen übertragen sondern gehen von der patienteneigenen Mikroflora aus [1 - 3]. Die Prävention endogener Infektionen ist allgemein jedoch mit größeren Schwierigkeiten verbunden und unterliegt eigenen Gesetzmäßigkeiten. Nur gegen einen kleineren Teil der endogenen Infektionen gibt es effektive Präventionsmöglichkeiten, insbesondere in Form einer Chemoprophylaxe (z.B. perioperative Antibiotikaprophylaxe, antivirale Prophylaxe bei stammzelltransplantierten Patienten) oder in Form einer Expositionsprophylaxe (z.B. Haut- und Schleimhaut-Antisepsis).

\section{Fazit für die Praxis}

Unkenntnisse über die spezifischen Übertragungswege der verschiedenen Infektionskrankheiten können nicht nur zu Ressourcenverschwendung führen, sondern auch zur Gefährdung von Patienten, medizinischem Personal und der Öffentlichkeit.

\section{Allgemeine Systematik der Übertragungswege von Infektionskrankheiten}

In der Humanmedizin folgt die Einteilung der Übertragungswege von Krankheitserregern klassischerweise der in Tab. 1 und Tab. 2 wiedergegebenen Systematik [4]. Es werden zunächst direkte und indirekte Übertragungsmechanismen unterschieden:

Direkte Übertragungswege. Die direkten Übertragungsmechanismen werden unterteilt in:

- direkte Kontaktübertragung (engl.: contact transmission) mit der Sonderform der Tröpfchenübertragung (engl.: droplet transmission)

- direkte Erregerexposition (engl.: direct exposure)

- diaplazentare Übertragung (engl.: transplacental transmission)

Indirekte Übertragungswege. Die indirekten Übertragungsmechanismen werden dagegen unterteilt in:

- vektor-assoziierte Übertragung (engl.: vector-borne transmission)=Vektorübertragung, Übertragung durch Arthropoden. Man unterscheidet die mechanische und die biologische Vektorübertragung.

- vehikel-assoziierte Übertragung (engl.: vehicle-borne transmission)=Vehikelübertragung, Übertragung durch Gegenstände und Substanzen. Ein Teil der Übertragungen durch Gegenstände kann auch als „indirekte Kontaktübertragung“ bezeichnet werden. 


\section{Tabelle 2}

Indirekte Übertragungsmechanismen (nach [4]).

\begin{tabular}{|c|c|c|}
\hline Bezeichnung & Erläuterung & Beispiele \\
\hline \multirow[t]{2}{*}{$\begin{array}{l}\text { vektor-assoziierte Über- } \\
\text { tragung }\end{array}$} & $\begin{array}{l}\text { mechanisch: aktive Übertragung durch Tiere (meist Arthro- } \\
\text { poden), wobei die Erreger mit Beinen, Saugrüssel (Proboscis) } \\
\text { oder Darminhalt übertragen werden, ohne dass sie sich im } \\
\text { Vektor vermehren oder weiter entwickeln }\end{array}$ & $\begin{array}{l}\text { Shigellen-Übertragung von Kot auf Nahrungsmittel mit den } \\
\text { Beinen von Schmeißfliegen }\end{array}$ \\
\hline & $\begin{array}{l}\text { biologisch: aktive Übertragung durch Tiere (meist Arthro- } \\
\text { poden), wobei sich die Erreger im Vektor vermehren und/ } \\
\text { oder weiter entwickeln }\end{array}$ & $\begin{array}{l}\text { Pest-Übertragung durch Flöhe; Malaria-Übertragung durch } \\
\text { Anophelesmücken }\end{array}$ \\
\hline $\begin{array}{l}\text { vehikel-assoziierte Über- } \\
\text { tragung }\end{array}$ & $\begin{array}{l}\text { Transport bzw. Einbringung von Erregern mit Hilfe von } \\
\text { Gegenständen oder Materialien durch eine geeignete Ein- } \\
\text { trittspforte in einen empfänglichen Wirt. In/auf den Gegen- } \\
\text { ständen/Materialien findet weder eine Vermehrung noch } \\
\text { eine Weiterentwicklung der Erreger statt. }\end{array}$ & $\begin{array}{l}\text { Gegenstände (engl.: fomites): Spielzeug, Kleidung, Bett- } \\
\text { wäsche, OP-Instrumente, Kanülen; } \\
\text { Materialien: Wasser, Nahrungsmittel, biologische Produkte } \\
\text { wie Blut, Serum, Plasma und Gewebe }\end{array}$ \\
\hline aerogene Übertragung & $\begin{array}{l}\text { Verbreitung von Erregern mit flüssigen oder festen } \\
\text { Schwebeteilchen }(<5 \mu \mathrm{m}) \text {, die in der Luft suspendiert sind } \\
\text { und bei Einatmen in die unteren Atemwege/Alveolen gelan- } \\
\text { gen. Gemische aus Schwebeteilchen und einem Gas werden } \\
\text { in der Physik als „Aerosol“ bezeichnet. Aerosole enthalten } \\
\text { keine größeren Tröpfchen oder Spritzer, da diese schnell } \\
\text { sedimentieren. Die aerogene Übertragung kann über Dis- } \\
\text { tanzen von weit über } 1 \mathrm{~m} \text { erfolgen, } \text { z. T. > } 1 \mathrm{~km}\end{array}$ & $\begin{array}{l}\text { Übertragung von Tuberkulose und Masern über weite } \\
\text { Strecken in Innenräumen; Übertragung von Legionellen aus } \\
\text { Rückkühlwerken über Distanzen von> } 1 \mathrm{~km} \text {; Übertragung } \\
\text { von Milzbrandsporen, die als biologische Waffe bzw. zu bio- } \\
\text { terroristischen Zwecken präpariert wurden }\end{array}$ \\
\hline
\end{tabular}

- aerogene Übertragung (engl.: airborne transmission) = Übertragung durch die Luft

Definition, Abgrenzung und Systematik der verschiedenen Übertragungswege sind zum einen wichtig, um sich über das Thema klar verständigen zu können. Zum anderen beruhen sie auf dem Bedürfnis, bestimmten Übertragungswegen die jeweils geeigneten Schutzmaßnahmen zuzuordnen bzw. aus den empirisch als effektiv ermittelten Schutzmaßnahmen Rückschlüsse auf die Übertragungswege zu machen.

\section{Systematik der Übertragungs- wege nosokomialer Infektionen}

Die oben aufgeführte allgemeine Systematik der Übertragungswege gilt prinzipiell auch für nosokomiale Infektionen, wobei Mechanismen wie die diaplazentare und die vektor-assoziierte Übertragung zumindest in den Industrieländern für die Übertragung nosokomialer Infektionen bedeutungslos sind. Bei den nosokomialen Infektionen ist aus praktischen Gründen die Zusammenfassung in 3 übergeordnete Kategorien sinnvoll:
- Übertragung aus Infektionsquellen der Umgebung

- Übertragung von Mensch zu Mensch

- endogene Übertragung

Infektionsquellen der Umgebung. Die Übertragung nosokomialer Infektionen aus Infektionsquellen in der unbelebten Umgebung ist selten und meist indirekt, kann z.T. aber dramatische Punktquellen-Ausbrüche verursachen [5]. Folgende Übertragungswege kommen vor:

- vehikel-assoziierte Übertragung (z.B. Salmonellosen durch kontaminierte Nahrungsmittel, HBV-Infektionen durch kontaminierte Blut- und Medizinprodukte)

- aerogene Übertragung aus der Umwelt (z. B. Aspergillosen bei Immunsupprimierten durch Verbreitung von Aspergillus-Konidien mit der Luft)

- Übertragung durch direkte Erregerexposition (z.B. Legionellosen durch Aspiration von erregerhaltigem Wasser [8])

Von Mensch zu Mensch. Die Übertragung nosokomialer Infektionen von Mensch zu Mensch ist erheblich häufiger als ihre Übertragung aus der Umwelt und ist Hauptgegenstand präventiver Bemühungen in der Patientenversorgung. Anhand der allgemeinen Syste- 
matik sind die wesentlichen Übertragungswege einzuteilen in die direkte Kontaktübertragung (einschl. Tröpfchenübertragung), die indirekte Kontaktübertragung und die aerogene Übertragung.

Wegen der praktischen Konsequenzen bezüglich der zu ergreifenden Präventionsmaßnahmen erfolgt die Unterteilung heute jedoch meist in folgende 3 Untergruppen $[6,7,9,11,15]$ :

- Kontaktübertragung (direkt und indirekt)

- Tröpfchenübertragung

- aerogene Übertragung

Endogene Übertragung. Endogene nosokomiale Infektionen, d. h. Infektionen durch Mikroorganismen der patienteneigenen Mikroflora, werden weder aus der Umgebung noch von anderen Personen erworben. Sie sind nach heutigem Kenntnisstand die häufigste Form nosokomialer Infektionen. Da hier nicht von einer Übertragung im eigentlichen Sinne gesprochen werden kann, werden sie nachfolgend nicht weiter betrachtet.

\section{Checkliste}

Übertragungswege von Mensch zu Mensch

Falls nosokomiale Infektionen nicht endogener Natur sind sondern von Mensch zu Mensch übertragen werden, so werden unter präventiven Aspekten 3 Mechanismen unterschieden:

- Kontaktübertragung

- Tröpfchenübertragung

- aerogene Übertragung

\section{Übertragung nosokomialer Infektionen: Umgebung vs. Mensch zu Mensch}

\section{Bedeutung der Krankenhausumgebung in der öffentlichen Wahrnehmung}

Für die meisten Laien und Medien sind Flächen und Gegenstände der unbelebten Krankenhausumgebung die wichtigste Quelle nosokomialer Infektionen. Die Überzeugung, dass „Krankenhauskeime“ durch „Schmutz“, „zu wenig Putzen“ und „mangelnde Hygiene“ übertragen werden, ist in der Öffentlichkeit tief verwurzelt und kaum korrigierbar. Für viele Laien ist es plausibler, dass postoperative Wundinfektionen durch die Verwendung schmutziger OP-Instrumente entste- hen als auf endogenem Wege, der aus wissenschaftlicher Perspektive wichtigsten Ursache [2].

\section{Bedeutung der Umgebung in der klinischen Realität}

In Wirklichkeit ist die Übertragung nosokomialer Infektionen aus der unbelebten Umgebung - sei es direkt oder indirekt über Arzneimittel, Medizinprodukte, Gegenstände, Wasser, Nahrung und Luft - in den Industrieländern selten. Wenn es jedoch auf diesem Weg tatsächlich zu nosokomialen Infektionen kommt, so sind diese besonders skandalträchtig. Denn nicht selten ist eine größere Zahl von Patienten betroffen (z.B. bei Ausbrüchen durch Salmonellen in Nahrungsmitteln oder durch herstellungsbedingte Kontamination von Parenteralia) und sie sind mit Ausnahme der aerogenen Übertragung oft zuverlässig durch technisch-organisatorische Maßnahmen vermeidbar (Tab. 3).

Gegenstand von Regulierungsmaßnahmen. Bei der Übertragung aus der unbelebten Umgebung mögen die beiden Faktoren „öffentliche Wahrnehmung“ und „leichte Vermeidbarkeit“ dafür mitverantwortlich sein, dass in Deutschland besonders viele Regulierungsmaßnahmen darauf abzielen, entsprechende Übertragungsrisiken zu verringern. Das betrifft sowohl verbindliche Rechtsnormen im Arzneimittel-, Medizinprodukte-, Lebensmittel-, Trinkwasser- und Abfallrecht als auch wirtschaftliche Normungsaktivitäten wie z.B. die DIN- und VDI-Normen im Bereich der Raumlufttechnik.

Umgebung und indirekte Kontaktübertragung. Systematisch betrachtet sind die meisten Übertragungsfälle sowohl aus der Umgebung als auch von Mensch zu Mensch der indirekten, vektor-assoziierten Übertragung zuzurechnen. Wie Tab. 3 zeigt, stammen die Erreger bei Übertragungsfällen aus der Umgebung oft von Mitpatienten, z.T. auch vom Personal, sodass hier auch von einer indirekten „Mensch-zu-Mensch-Übertragung“ gesprochen werden kann, bei der Arzneimittel, Medizinprodukte, Gegenstände und Nahrung als Übertragungsvehikel dienen. Im Kapitel „Kontaktübertragung von Mensch zu Mensch“ wird nochmals besonders auf die Fälle eingegangen, bei denen die Hände und Handschuhe des Personals sowie häufig berührte Flächen und Gegenstände als Übertragungsvehikel dienen. 


\section{Tabelle 3}

Beispiele nosokomialer Infektionen nach direkter oder indirekter Übertragung aus der unbelebten Umgebung.

\begin{tabular}{|c|c|c|}
\hline Übertragung & Beispiele nosokomialer Infektionen & Prävention \\
\hline direkt aus der Umgebung & $\begin{array}{l}\text { Legionellosen bei Intensivpatienten durch Aspiration von } \\
\text { legionellenhaltigem Leitungswasser [8] }\end{array}$ & $\begin{array}{l}\text { ausschließliche Verwendung von sterilem Wasser für die } \\
\text { Magensonden-Ernährung }\end{array}$ \\
\hline \multirow[t]{2}{*}{$\begin{array}{l}\text { indirekt, nahrungsmittel- } \\
\text { assoziiert }\end{array}$} & $\begin{array}{l}\text { Salmonellose-Ausbruch durch Salmonella Enteritidis nach } \\
\text { deren Vermehrung in eierhaltigen Speisen }\end{array}$ & $\begin{array}{l}\text { Beachtung der Erhitzungstemperatur sowie der anschließen- } \\
\text { den Lagertemperaturen und -zeiten in der Küche, beim Trans- } \\
\text { port und auf den Stationen }\end{array}$ \\
\hline & $\begin{array}{l}\text { Norovirus-Ausbruch durch Ausscheider unter den Küchen- } \\
\text { mitarbeitern }\end{array}$ & $\begin{array}{l}\text { Tätigkeitsverbot während und einige Zeit nach einer } \\
\text { Gastroenteritis. Händehygiene nach dem Toilettenbesuch }\end{array}$ \\
\hline \multirow[t]{2}{*}{$\begin{array}{l}\text { indirekt, medizin- } \\
\text { produkte-assoziiert }\end{array}$} & $\begin{array}{l}\text { Pseudomonas-aeruginosa-Infektionen bei Intensivpatienten } \\
\text { durch Zwischenlagerung von Medizinprodukten im Wasch- } \\
\text { becken vor Anwendung am Patienten }\end{array}$ & $\begin{array}{l}\text { keine Verwendung von Waschbecken zur Lagerung von } \\
\text { Medizinprodukten vor Anwendung am Patienten; Wasch- } \\
\text { becken immer als kontaminiert betrachten }\end{array}$ \\
\hline & Übertragung von Hepatitis B mit einem Duodenoskop & $\begin{array}{l}\text { Dichtigkeitsprüfung und gründliche Vorreinigung von } \\
\text { Endoskopen, anschließend Desinfektion mit einem viruziden } \\
\text { Verfahren }\end{array}$ \\
\hline \multirow[t]{2}{*}{$\begin{array}{l}\text { indirekt, arzneimittel- } \\
\text { assoziiert }\end{array}$} & $\begin{array}{l}\text { Hepatitis-C-Infektion nach Injektion eines mit HCV kontami- } \\
\text { nierten Arzneimittels aus Mehrdosisbehälter }\end{array}$ & $\begin{array}{l}\text { Vermeidung von Mehrdosisbehältern. Falls notwendig, diese } \\
\text { nur mit jeweils neuer, steriler Spritze und Kanüle anstechen }\end{array}$ \\
\hline & $\begin{array}{l}\text { Sepsis durch Yersinia enterocolitica nach Transfusion eines } \\
\text { kontaminierten Erythrozyten-Konzentrats }\end{array}$ & $\begin{array}{l}\text { sorgfältige Blutspender-Auswahl, keine Spende nach zurück- } \\
\text { liegender Diarrhö }\end{array}$ \\
\hline \multirow[t]{2}{*}{ indirekt, aerogen } & $\begin{array}{l}\text { invasive Aspergillose im Rahmen einer allogenen Stamm- } \\
\text { zelltransplantation (SZT) }\end{array}$ & $\begin{array}{l}\text { problematisch, da endogene Reaktivierung vorausgegange- } \\
\text { ner Kolonisationen und Manifestation> } 100 \text { Tage nach SZT } \\
\text { möglich }\end{array}$ \\
\hline & & $\begin{array}{l}\text { Unterbringung von Patienten mit anhaltender Granulozyto- } \\
\text { penie in Räumen mit Luftüberdruck und schwebstoffgefil- } \\
\text { terter Zuluft wird empfohlen, kann Aspergillose aber nur z. T. } \\
\text { verhindern. Außerhalb solcher Räume Schutz der Patienten } \\
\text { mit Atemschutzmasken (z. B. FFP2) }\end{array}$ \\
\hline
\end{tabular}

\section{Prävention der Übertragung aus der Umgebung durch Standard-/Basishygiene}

Allgemeines Ziel sollte es in der Patientenversorgung sein, einen praktikablen Mindeststandard zur Minimierung des Übertragungsrisikos aus der Umgebung zu etablieren. Derartige, bei allen Patienten diagnoseunabhängig zu beachtenden Standardmaßnahmen wurden von den US-amerikanischen Centers for Disease Control and Prevention (CDC) definiert und als „Standard Precautions" bezeichnet (s. Checkliste auf der nächsten Seite) [6, 9-11]. In der deutschsprachigen Fachliteratur werden sie teilweise als „Standardhygiene“, teilweise als „Basishygiene“bezeichnet [12-14]. Aus der in der Checkliste aufgelisteten Aufstellung zu den Standard Precautions ist ersichtlich, dass die meisten Komponenten auch auf eine Minimierung des Übertragungsrisikos aus der Umgebung abzielen. Mit einigen relevanten Bereichen der Patientenumgebung wie Küche und Rückkühlwerken befassen sich die Standard Precautions dagegen nicht.

Ziel der Standard Precautions ist nicht die absolute Sicherheit vor nosokomialen Übertragungen, sondern deren Minimierung mit kosteneffektiven Mitteln.

Bei einzelnen Übertragungsfällen, insbesondere aber im Falle eines Ausbruchs aufgrund einer Erregerübertragung aus der unbelebten Umwelt müssen die Infektionsquellen und Übertragungswege analysiert und möglichst schnell eliminiert werden [5]. 


\section{Checkliste}

Standard Precautions (Standard-/Basishygiene)

Die Standard Precautions (deutsch: Standard- oder Basishygiene) bezwecken die kosteneffektive Minimierung des Risikos von Infektionsübertragungen im Rahmen der Patientenversorgung. Gemäß aktueller CDC-Leitlinie sind sie diagnoseunabhängig, d. h. unabhängig von irgendeiner vermuteten oder nachgewiesenen Infektionskrankheit, bei allen Patienten umzusetzen und bestehen aus folgenden 10 Komponenten $[6,10,15]$ :

- Händehygiene gemäß den gängigen Indikationen

- richtiger Gebrauch persönlicher Schutzausrüstung (Schutzhandschuhe; Mund-, Nasen-, Augenschutz; Schutzkittel) bei wahrscheinlichem Kontakt mit Blut, Körperflüssigkeiten, Sekreten oder Ausscheidungen

- korrekte Handhabung und Aufbereitung von Pflegeutensilien/Medizinprodukten, die mit Blut, Körperflüssigkeiten, Sekreten oder Ausscheidungen kontaminiert sind

- routinemäßige Reinigung/Desinfektion häufig berührter Oberflächen der Patientenumgebung

- korrekte Handhabung von Bettwäsche, die mit Blut, Körperflüssigkeiten, Sekreten oder Ausscheidungen kontaminiert ist
- Schutz des medizinischen Personals vor blutübertragenen Erregern durch Vermeidung von Verletzungen mit scharfen/spitzen Gegenständen und von Schleimhautkontakt

- Einzelunterbringung von Patienten, die ihre Umgebung kontaminieren

- richtiges Verhalten beim Husten, Niesen und Schnäuzen

- sichere Injektions- und Infusionstechnik

- infektionspräventive Maßnahmen bei Punktionen im Bereich des Wirbelkanals

\section{Kontaktübertragung von Mensch zu Mensch}

„Schmierinfektion“? Die Kontaktübertragung (engl.: contact transmission) ist der häufigste Übertragungsweg nosokomialer Infektionen und wird in der deutschen Fachliteratur teilweise immer noch als „Schmierinfektion“ bezeichnet, obwohl sie nur selten mit sichtbarem „Verschmieren“ von Körperausscheidungen und -flüssigkeiten einhergeht und nicht zwangsläufig eine Infektion zur Folge hat, sondern auch zu einer Kolonisation führen kann. Der Begriff „Kontaktübertragung“ trägt dagegen der Tatsache Rechnung, dass Mikroorganismen auch durch Berührung trockener Oberflächen und unsichtbar kontaminierter Gegenstände übertragen werden können.

\section{Mechanismen der Kontaktübertragung von Mensch zu Mensch}

Direkte Kontaktübertragung. Es wird zwischen der direkten und indirekten Kontaktübertragung unterschieden $[6,7,9,15]$. Die direkte Kontaktübertragung gemäß der Definition in Tab. 1 kommt in der Patientenversorgung selten vor.

Die direkte Kontaktübertragung findet häufiger zwischen Patienten und medizinischem Personal statt als zwischen Patienten.
Beispiele für die direkte Kontaktübertragung aus der Praxis sind:

- Übertragung von Scabies (Krätze) bei der Umlagerung eines Patienten

- Übertragung von Dermatophyten (Hautpilzen) in kleine Hautläsionen der Hände und Unterarme im Rahmen von Pflegemaßnahmen

- Übertragung von Herpes-simplex-Virus auf einen Finger mit Hautläsion (herpetisches Panaritium, Whitlow) bei der Untersuchung der Mundhöhle

Wichtigste Maßnahme zur Prävention der direkten Kontaktübertragung ist die Verwendung von persönlicher Schutzausrüstung wie Schutzhandschuhen und Schutzkitteln zur Schaffung einer mechanischen Barriere zwischen dem infektiösen Patienten und dem Personal.

Indirekte Kontaktübertragung. Die indirekte (vehikelassoziierte) Kontaktübertragung ist dagegen die häufigste Form der Übertragung nosokomialer Infektionen von Mensch zu Mensch und der häufigste Übertragungsweg fäkal ausgeschiedener oder multiresistenter Erreger [6]. Als zwischengeschaltete Übertragungsvehikel (s. Tab. 2) dienen am häufigsten die Hände und Handschuhe des Personals, aber auch häufig berührte Flächen und Gegenstände wie Türgriffe, Wasserarmaturen, und Computertastaturen kommen infrage, insbesondere wenn die Regeln der Händedesinfektion und des Gebrauchs von Schutzhandschuhen nicht beachtet werden. Wegen der oft höheren mikrobiellen Last und der meist kürzeren Kontaktintervalle werden mit Hän- 
den und Handschuhen im Allgemeinen erheblich häufiger Erreger und ein größeres Erregerspektrum übertragen als mit Medizinprodukten und anderen Gegenständen der Patientenumgebung. Letztere können besonders bei der Übertragung umweltresistenter Erreger wie Noroviren, Enterokokken, Staphylokokken, Acinetobacter und Clostridium difficile eine Rolle spielen. Wie folgende Beispiele zeigen, erfolgt die indirekte Kontaktübertragung meist von Patient zu Patient:

- Übertragung von Staphylococcus aureus beim Verbandwechsel durch Berührung einer S.-aureus-infizierten Wunde mit den Handschuhen und Fortführung des Verbandwechsels bei einem anderen Patienten, ohne zwischenzeitlich die Handschuhe zu wechseln und die Hände zu desinfizieren

- Übertragung von Rotaviren auf einer pädiatrischen Station durch gemeinsam benutztes Spielzeug

\section{Maßnahmen zur Prävention der Kontaktübertragung von Mensch zu Mensch}

\section{Prävention der Kontaktübertragung durch Standard-} Basishygiene. Die direkte und indirekte Kontaktübertragung lässt sich prinzipiell größtenteils durch konsequente Umsetzung der ohnehin bei allen Patienten zu beachtenden Standard Precautions (Standard-/Basishygiene $[6,10,15])$ verhindern. Allein die ersten 4 Komponenten (Händehygiene, richtiger Gebrauch der persönlichen Schutzausrüstung, MedizinprodukteAufbereitung, Reinigung der Patientenumgebung) tragen wesentlich zur Verringerung der Übertragungsrisiken bei und sind die entscheidenden Maßnahmen zur Vermeidung der Übertragung multiresistenter Erreger. In der Tat wird derzeit diskutiert, ob es aufgrund der Studienlage überhaupt noch gerechtfertigt ist, Patienten mit MRSA-Nachweis räumlich zu isolieren oder ob nicht konsequent umgesetzte Standardhygiene mindestens ebenso erfolgreich ist $[3,16,17]$.

Kontaktisolierung. In der Praxis werden die Standard Precautions selten vollständig umgesetzt und sie betreffen fast ausschließlich das Personal, nicht aber die Aktivitäten von Patienten und Besuchern. Bei leicht durch Kontakt übertragbaren und klinisch/epidemiologisch relevanten Infektionskrankheiten sowie bei Ausbrüchen durch kontaktübertragene Erreger werden die Standard Precautions daher nicht als ausreichend angesehen, und es wird empfohlen, diese zum Schutz von Mitpatienten und Personal mit einer Kontaktisolierung zu kombinieren [6, 7, 9,11,15,18]. Für die Dauer der Infektiosität umfasst die Kontaktisolierung (engl.: contact precautions, contact isolation) im Wesentlichen folgende Maßnahmen:

- Einzelzimmerunterbringung (bei mehreren Patienten mit gleichem Erreger ggf. als Kohorte in einem Zimmer), die Zimmertüre muss nicht geschlossen bleiben.

- Der isolierte Patient verlässt das Zimmer nur in begründeten Ausnahmefällen und in Absprache mit dem Personal.

- Das Personal trägt bei Kontakt mit dem Patienten und potenziell kontaminierten Gegenständen Schutzhandschuhe und Schutzkittel. Als Alternative zum generellen Gebrauch von Schutzhandschuhen sind bei der Kontaktisolierung immer auch Händedesinfektion und Handschuhgebrauch gemäß den Regeln der Standard Precautions (Standard-/Basishygiene) zu erwägen. Der generelle Gebrauch von Schutzhandschuhen ist dagegen bei der Isolierung von Patienten mit Norovirus- und Clostridium-difficileInfektionen von Bedeutung; nach dem Ausziehen ist eine Händedesinfektion erforderlich.

Die Isolierungs-Leitlinie der CDC enthält als Appendix A eine alphabetische Liste von Infektionskrankheiten und Erregern, in der aufgrund klinisch-epidemiologischer Daten vermerkt ist, in welchen Fällen die Standard Precautions ausreichen und in welchen diese mit übertragungsspezifischen Isolierungsmaßnahmen wie der Kontaktisolierung kombiniert werden sollten [6]. Bei einzelnen Erregern wie bei MRSA und Clostridium difficile wird derzeit diskutiert, ob die Kontaktisolierung in endemischen Situationen tatsächlich notwendig und verhältnismäßig ist $[3,16,19]$.

\section{Tipp für die Praxis}

In epidemischen Situationen ist die Kontaktisolierung eines der wichtigsten Instrumente zur Eindämmung von Ausbrüchen durch Erreger, die durch Kontakt übertragen werden [5].

\section{Tröpfchenübertragung von Mensch zu Mensch}

\section{Sonderform der direkten Kontaktübertragung. Im}

Kapitel „Allgemeine Systematik der Übertragungswege von Infektionskrankheiten“ wurde bereits festgestellt, dass die Tröpfchenübertragung (engl.: droplet transmission) eine Sonderform der direkten Kontaktübertragung ist und dass sich ihr Übertragungsmechanismus deutlich von dem der aerogenen Übertragung unterscheidet. Entsprechend unterschiedlich sind auch 


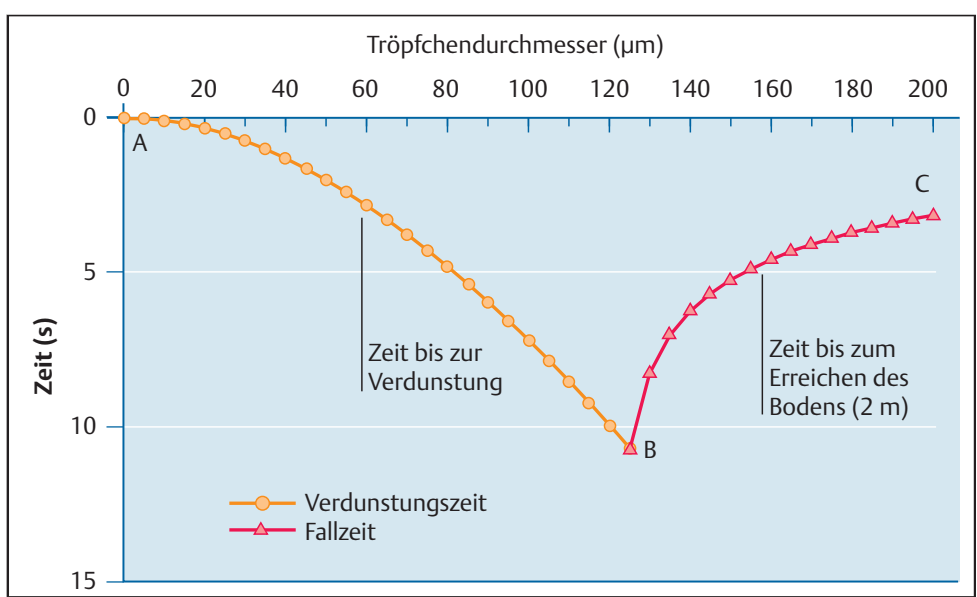

Abb. 1 Verdunstungszeit und Fallzeit von Wassertröpfchen unterschiedlichen Durchmessers bei $0 \%$ relativer Luftfeuchtigkeit (nach [27]).

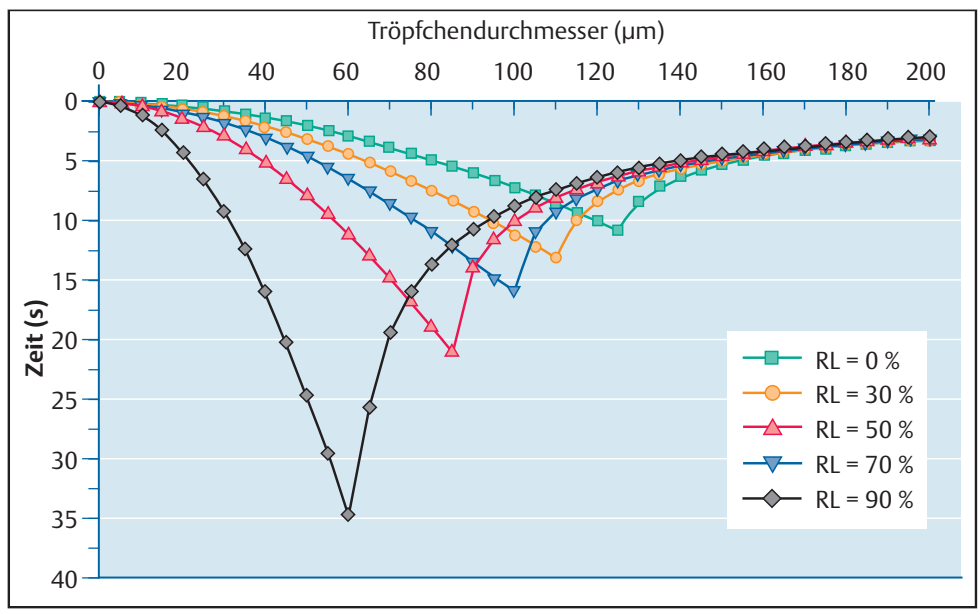

Abb. 2 Verdunstungszeit und Fallzeit von Wassertröpfchen verschiedener Durchmesser bei unterschiedlichen Werten für die relative Luftfeuchtigkeit (RL) (nach [27]).

die jeweiligen Präventionsmaßnahmen. Im Gegensatz zur direkten Kontaktübertragung werden bei der Tröpfchenübertragung Erreger über kurze Strecken von meist $<1 \mathrm{~m}$ direkt aus dem Respirationstrakt einer Person durch die Luft auf empfängliche Schleimhautareale einer anderen Person geschleudert. In der deutschen Fachliteratur wird die Tröpfchenübertragung teilweise auch als „Tröpfcheninfektion“ bezeichnet, obwohl sie nicht zwangsläufig zu einer Infektion führt, sondern auch lediglich eine Kolonisation zur Folge haben kann.

Korrekt ist nur die Bezeichnung Tröpfchenüber-

tragung, weil nicht jede Übertragung auch zu einer Infektion führt.

\section{Mechanismen der Tröpfchenübertragung von Mensch zu Mensch}

Unsere Kenntnisse über die Mechanismen der Tröpfchenübertragung stammen aus epidemiologischen Ausbruchsanalysen, Simulationsstudien und laborexperimentellen Untersuchungen der Aerosol-Dynamik [20-28].

Laborexperimente. Schon seit den 1930er-Jahren wurden Versuche unternommen, das Verhalten und die Reichweite respiratorischer Tröpfchen zu beschreiben $[25,28]$. Durch physiologische Aktivitäten wie Husten, Niesen und Sprechen gelangen respiratorische Tröpfchen auf eine ballistische Bahn, deren effektive Reichweite von Faktoren wie Impuls und Ausstoßgeschwindigkeit, Dichte und Trägheit sowie von Umgebungsparametern wie Temperatur, Luftfeuchtigkeit, Luftbewegung und Reibung abhängt wie auch der Fähigkeit eines Mikroorganismus, über diese Strecke seine Infektiosität zu bewahren.

In einem stark vereinfachten Modell mit vertikal fallenden Tröpfchen aus reinem Wasser von einer Temperatur von initial $33^{\circ} \mathrm{C}$ in stagnierender Luft von $0 \%$ relativer Luftfeuchtigkeit lässt sich das aerodynamische Verhalten von Tröpfchen mithilfe der in Abb. 1 wiedergegebenen „Verdunstungs-Fall-Kurve“ darstellen [27]. Die Kurve AB beschreibt darin die Verdunstungszeit der Tröpfchen in Abhängigkeit von ihrem initialen Durchmesser und die Kurve BC die Dauer des vertikalen Falls bis die Tröpfchen über eine Strecke von $2 \mathrm{~m}$ den Boden erreicht haben. Abb. 1 zeigt, dass in diesem Modell Tröpfchen von wenigen $\mu \mathrm{m}$ Durchmesser innerhalb von Bruchteilen einer Sekunde verdunsten und dass die Verdunstungszeit mit zunehmender Tröpfchengröße ansteigt. Unter den genannten experimentellen Bedingungen erreichen erst Tröpfchen ab dem kritischen Durchmesser von initial $125 \mu \mathrm{m}$ den Boden, bevor sie vollständig verdunsten können. Mit weiter zunehmender Tröpfchengröße verringert sich anschließend die Zeit bis zur Sedimentation auf der Bodenoberfläche. Bei einem Tröpfchendurchmesser von $125 \mu \mathrm{m}$ beträgt die Sedimentationszeit ca. 10 Sekunden, bei $200 \mu \mathrm{m}$ weniger als 5 Sekunden. Abb. 2 zeigt, wie sich das aerodynamische Verhalten von Tröpfchen durch Veränderung nur eines Umgebungsparameters, nämlich der relativen Luftfeuchtigkeit, verändert: Tröpfchen verdunsten in feuchter Luft langsamer und sedimentieren dadurch schneller als in trockener Luft. Die kritische Tröpfchengröße sinkt daher von $125 \mu \mathrm{m}$ auf $60 \mu \mathrm{m}$, wenn die relative Luftfeuchtigkeit von 0 auf $90 \%$ steigt. 
Grenzen laborexperimenteller Untersuchungen. Das Beispiel zeigt, wie problematisch es ist, mithilfe derart vereinfachender Modelle das Verhalten respiratorischer Tröpfchen unter realen Bedingungen zu simulieren. Die Realität ist erheblich komplexer als solche Laborexperimente: Respiratorische Tröpfchen bestehen nicht aus reinem Wasser und die darin enthaltenen Salze, organischen Substanzen, Mikroorganismen und anderen Partikel verdunsten nicht. Nach Abschluss des Verdunstungsprozesses bleiben daher sog. „Tröpfchenkerne“ (engl.: droplet nuclei) zurück.

Respiratorische Tröpfchen werden darüber hinaus, z.B. beim Husten oder Niesen, mit einer bestimmten Geschwindigkeit in mehr oder weniger turbulente Luftverhältnisse ausgestoßen und durch Reibungskräfte wieder abgebremst.

Überhaupt keine Auskunft geben solche Experimente darüber, wie lange Mikroorganismen innerhalb der emittierten Tröpfchen oder Tröpfchenkerne unter Einwirkung von Stressfaktoren wie Temperaturabfall, Austrocknung, Licht und UV-Strahlung ihre Infektionsfähigkeit beibehalten [29].

Der Nachweis von Erreger-Nukleinsäuren in Tröpfchen oder Tröpfchenkernen ist nicht mit dem

Nachweis von Infektiosität zu verwechseln $[30,31]$.

Laborexperimente liefern zwar wichtige Beiträge zum Verständnis der Transmissionsvorgänge. Ausschlaggebend zur Beantwortung der Fragen, über welche Distanzen Tröpfchen in der Praxis infektiologisch effektiv übertragen werden können und mit welchen Schutzmaßnahmen man eine Tröpfchenübertragung effektiv verhindern kann, sind letztlich aber nicht Laborexperimente sondern klinisch-epidemiologische Beobachtungen und Studien.

Respiratorische Tröpfchen. Beim Husten, Niesen und Sprechen, besonders aber bei medizinischen Maßnahmen wie Bronchoskopie, Intubation, endotrachealem Absaugen, Sputuminduktion, Thorax-Physiotherapie und kardiopulmonaler Wiederbelebung werden Tröpfchen von respiratorischem Sekret ausgestoßen. Der weitaus größte Teil des ausgestoßenen Sekretvolumens besteht aus größeren Tröpfchen, die nur eine Strecke von $<1 \mathrm{~m}$ zurücklegen und nicht in der Luft suspendiert bleiben $[6,7,11]$.
Empfängliche Eintrittspforten für tröpfchenübertragene Erreger sind die Konjunktiven sowie die Schleimhäute des Mund-Nasen-Rachen-Raums $[7,32]$.

Tiefere Abschnitte der Atemwege oder gar die Lungenalveolen werden von solchen Tröpfchen nicht erreicht. Über die Entfernungen, die Sekrettröpfchen unter physiologischen Bedingungen maximal zurücklegen können, gibt es derzeit keine allgemeingültigen Erkenntnisse. Strecken von bis zu $6 \mathrm{~m}$ sind unter laborexperimentellen Bedingungen gemessen worden [27], aufgrund von klinisch-epidemiologischen Untersuchungen und Simulationsstudien ist jedoch bekannt, dass tröpfchenübertragbare respiratorische Erreger in aller Regel nur über kürzere Distanzen übertragen werden $[6,23,24]$.

Klassischerweise gilt der Abstand von $\leq 1 \mathrm{~m}$ als der Bereich, innerhalb dessen man sich bei einem infektiösen Patienten vor einer Tröpfchenübertragung schützen muss. Diese kurze Distanz erklärt sich nicht nur durch die geringe Reichweite der Tröpfchen, sondern auch dadurch, dass tröpfchenübertragene Erreger ihre Infektiosität rasch verlieren und nicht über lange Strecken beibehalten [6]. Experimente mit Pockenviren und Untersuchungen im Rahmen der SARS-Pandemie im Jahre 2003 (Severe acute respiratory syndrome, verursacht durch das SARS-assoziiertes Coronavirus [SARS-CoV]) haben jedoch Hinweise darauf gegeben, dass infektiöse Tröpfchen von Patienten mit diesen beiden Krankheiten auch Personen im Umkreis von 2-3m infizieren können [21,33]. Aufgrund dieser Erkenntnisse gilt heute nach wie vor der Umkreis von $1 \mathrm{~m}$ um einen Patienten mit einer tröpfchenübertragenen Infektionskrankheit als der Bereich, innerhalb dessen man sich normalerweise vor einer Tröpfchenübertragung zu schützen hat. Kritisch ist somit in aller Regel der kurze Abstand zwischen 2 Personen, der sog. „Faceto-Face-Kontakt“.

\section{Tipp für die Praxis}

Sicherheitshalber sollte man sich bei hoch kontagiösen und bisher unbekannten Erregern bereits im Abstand von 2-3m oder sogar schon bei Betreten des Patientenzimmers mit einem Mund-Nasen-Schutz vor einer Tröpfchenübertragung schützen $[6,15]$. 
Tröpfchen und Spritzer anderer Körperflüssigkeiten. Die Tröpfchenübertragung wurde am besten bei respiratorischen Erregern untersucht. Prinzipiell können aber auch Tröpfchen und Spritzer von Blut und anderen Körperflüssigkeiten auf diesem Weg übertragen werden, z. B. bei Operationen oder beim Erbrechen. Eintrittspforten sind auch hier in aller Regel die Konjunktiven sowie die Schleimhäute des Mund-NasenRachen-Raums; über die Transmissionsstrecken und Präventionsmaßnahmen gilt ähnliches wie bei den respiratorischen Tröpfchen. $[6,11]$

\section{Maßnahmen zur Prävention der Tröpfchen- übertragung von Mensch zu Mensch}

Zur Prävention der Tröpfchenübertragung muss verhindert werden, dass infektiöse Tröpfchen und Spritzer auf die Konjunktiven und die Schleimhäute des MundNase-Rachen-Raums gelangen. Erzielt wird das durch Einhaltung eines Abstands von üblicherweise $1 \mathrm{~m}$ und/ oder durch geeignete persönliche Schutzausrüstung, nämlich durch Schutzbrillen und Visiere sowie durch den auch als „OP-Maske“ (engl.: surgical mask, medical mask, procedure mask) bezeichneten Mund-NasenSchutz $[6,11,15,34]$

Prävention der Tröpfchenübertragung durch Standard-/Basishygiene. Teil der bei allen Patienten - unabhängig von deren Infektionsstatus -zu beachtenden Standard Precautions (Standard-/Basishygiene) ist die richtige Verwendung von persönlicher Schutzausrüstung $[6,10,15]$. Hierzu zählt das Tragen einer OP-Maske und eines Augenschutzes bei allen Maßnahmen am Patienten, bei denen das Risiko besteht, dass Tröpfchen oder Spritzer von Blut, Sekreten oder anderen Körperflüssigkeiten freigesetzt bzw. versprüht werden, z. B. bei Intubation, Extubation und offenem endotrachealen Absaugen. Als geeignete Schutzausrüstung wird genannt:

- Mund-Nasen-Schutz und Schutzbrille

- Mund-Nasen-Schutz mit integriertem Visier

- Visier, das die Vorderseite und die Seiten des Gesichts vollständig bedeckt

Tröpfchenisolierung. Bei stationären Patienten mit leicht durch Tröpfchen übertragbaren und klinisch/ epidemiologisch relevanten Infektionskrankheiten werden die Standard Precautions nicht als ausreichend

\section{Hintergrundwissen}

Schutzwirkung des Mund-Nasen-Schutzes (= OP-Maske)

Der Mund-Nasen-Schutz (MNS) ist ein Medizinprodukt und schützt die Schleimhaut von Mund, Nase und Rachen des Trägers nicht nur vor eigener Berührung sondern auch vor tröpfchenübertragenen Infektionskrankheiten, die mit größeren Tröpfchen und Spritzern, z. B. von Blut, Sekreten und Ausscheidungen, über eine Entfernung von meist nicht mehr als $1 \mathrm{~m}$ übertragen werden. Gleichzeitig schützt er vor der Abgabe von Sekrettröpfchen aus den Atemwegen des Trägers. In der Patientenversorgung wird er auf folgende Arten eingesetzt [6, 11, 15, 34]:

- Der MNS wird vom medizinischen Personal getragen, um die eigene Mund-, Nasen- und Rachenschleimhaut vor Tröpfchen und Spritzern von Blut, Sekreten, Ausscheidungen u. a. Körperflüssigkeiten zu schützen. Er verhindert auch den Kontakt von Mund und Nase mit den eigenen kontaminierten Händen und Fingern.
- Der MNS wird vom medizinischen Personal bei Operationen und anderen invasiven Eingriffen auch getragen, um zu verhindern, dass Mikroorganismen des eigenen Mund-Nasen-RachenRaums mit respiratorischen Tröpfchen in die Wunde des Patienten gelangen.

- Der MNS wird Patienten mit kontagiösen Atemwegsinfektionen angelegt, um die Verbreitung infektiöser Atemwegssekrete zu begrenzen.

Der MNS schützt allein schon aufgrund der undefinierten Filtrationsleistung nicht vor der Inhalation kleinster, in der Luft suspendierter Schwebeteilchen (z. B. Tröpfchenkerne). Der MNS schließt darüber hinaus nicht dicht mit der Haut des Trägers ab, sodass Luft mit Schwebeteilchen beim Einatmen nicht vollständig das Vliesmaterial des MNS passiert, sondern durch Lücken zwischen MNS und Haut in die Atemwege gelangen kann. Diese auch als „Leckage“ bezeichnete Luftmenge ist von infektiologischer Bedeutung für die aerogene Übertragung - d. h. im Falle, dass die Schwebeteilchen infektiöse Erreger enthalten - nicht jedoch für die Tröpfchenübertragung.

Den MNS gibt es in unterschiedlichen Ausführungen, wobei unbekannt ist, welche Art am besten vor einer Tröpfchenübertragung schützt. In Europa sind Leistungsanforderungen an den MNS und entsprechende Prüfverfahren in der DINEN 14683 festgelegt. In den USA werden von OP-Masken (engl. surgical masks) wasserabweisende (fluid-resistant) Eigenschaften und eine Zulassung durch die FDA (Food and Drug Administration) gefordert, während die Ausführung anderer Formen des MNS (engl.: procedure masks, isolation masks) nicht reguliert ist $[6,11]$. 
angesehen, und es wird empfohlen, diese zum Schutz von Mitpatienten und Personal mit einer Tröpfchenisolierung (engl.: droplet precautions, droplet isolation) zu kombinieren $[6,7,9,11,15,18]$.

Wichtig ist die Tröpfchenisolierung bei Ausbrüchen durch tröpfchenübertragene Erreger [5].

Für die Dauer der Infektiosität umfasst die Tröpfchenisolierung im Wesentlichen folgende Maßnahmen [6]:

- Einzelzimmerunterbringung (bei mehreren Patienten mit gleichem Erreger, ggf. als Kohorte in einem Zimmer); die Zimmertüre muss nicht geschlossen bleiben; spezielle Raumlufttechnik ist nicht erforderlich. Falls kein Einzelzimmer verfügbar ist, kann der infektiöse Patient mit anderen Patienten zusammengelegt werden, sofern gewährleistet ist, dass zwischen den Patienten ein Abstand von > 1 m eingehalten wird.

- Beim Betreten des Isolierzimmers legen Personal und Besucher einen Mund-Nasen-Schutz an. Ungeklärt ist, ob es (über die Forderungen der Standard Precautions hinaus) sinnvoll ist, in der Nähe von tröpfchenisolierten Patienten routinemäßig einen Augenschutz zu tragen.

- Der isolierte Patient verlässt das Zimmer nur in begründeten Ausnahmefällen und in Absprache mit dem Personal. Außerhalb des Isolierzimmers trägt der Patient einen Mund-Nasen-Schutz.

Die Isolierungs-Leitlinie der CDC enthält als Appendix A eine alphabetische Liste von Infektionskrankheiten und Erregern, in der aufgrund klinisch-epidemiologischer Daten vermerkt ist, in welchen Fällen die Standard Precautions ausreichen und in welchen diese mit übertragungsspezifischen Isolierungsmaßnahmen wie der Tröpfchenisolierung kombiniert werden müssen [6]. Zu den Infektionskrankheiten, die bei Nachweis oder begründetem Verdacht eine Tröpfchenisolierung erforderlich machen, zählen demnach z.B.:

- invasive Haemophilus-influenzae-Typ-B- Infektionen

- Meningokokken-Infektionen

- Pneumonien durch Mycoplasma pneumoniae

- Pertussis

- Mumps

- Röteln

- Parvovirus-B19-Infektionen

\section{Tipp für die Praxis}

Influenza wird in der klinischen Praxis ganz überwiegend durch Tröpfchen übertragen, seltener auch durch Kontakt; in wenigen beschriebenen Fällen haben möglicherweise auch Übertragungen über Distanzen von $>1 \mathrm{~m}$ stattgefunden.

\section{Aerogene Übertragung von Mensch zu Mensch}

Im Kapitel „Allgemeine Systematik der Übertragungswege von Infektionskrankheiten“ wurde bereits festgestellt, dass die aerogene Übertragung (Synonym: Luftübertragung, engl.: airborne transmission) zu den indirekten Übertragungswegen zählt und sich fundamental vom direkten Mechanismus der Tröpfchenübertragung unterscheidet.

Die aerogene Übertragung ist selten und erfolgt mit Hilfe von nicht-sedimentierenden Schwebeteilchen (i.d. R. Tröpfchenkernen).

Da man ein Gemisch aus Schwebeteilchen und Luft auch als „Aerosol“ bezeichnet, wird die aerogene Übertragung auch „Aerosol-Übertragung“ (engl.: aerosol transmission) genannt.

Der aerogene Übertragungsweg ist nur bei wenigen Infektionskrankheiten beschrieben, er erfordert aber die technisch aufwendigsten Präventionsmaßnahmen.

\section{Definition}

Aerosol

In der Naturwissenschaft wird ein Gemisch aus flüssigen oder festen Schwebeteilchen und einem Gas gewöhnlich Luft - als „Aerosol“ bezeichnet. Die Schwebeteilchen eines Aerosols sind im Trägergas suspendiert und unterliegen keinen oder nur sehr langsamen Sedimentationsprozessen.

Umgangssprachlich (teilweise auch in der Medizin) werden fälschlicherweise manchmal auch größere, rasch sedimentierende Tröpfchen nach Versprühen oder Verspritzen in die Luft als „Aerosol“ bezeichnet. 


\section{Mechanismen der aerogenen Übertragung von Mensch zu Mensch}

Die aerogene Übertragung erfolgt mit inhalierbaren (lungengängigen) Schwebeteilchen, wenn diese Erreger enthalten, die über längere Strecken und Zeitspannen ihre Infektiosität bewahren $[6,7,11,15,35]$. Ein Aerosol mit derartigen „luftgetragenen“ Erregern kann sich mit der Luftströmung über weite Strecken im Innenraumbereich verteilen und bei empfänglichen Personen nach Inhalation in tiefe Lungenabschnitte Infektionen hervorrufen, auch wenn diese Personen keinen „Face-to-Face-Kontakt“ mit einem infektiösen Patienten hatten oder wenn sie sich mit diesem nicht einmal im selben Raum aufgehalten haben. Bei der aerogenen Übertragung von Mensch zu Mensch sind die Erreger in aller Regel in Tröpfchenkerne eingeschlossen, dem Austrocknungsprodukt respiratorischer Tröpfchen (s. Kapitel „Mechanismen der Tröpfchenübertragung von Mensch zu Mensch“). Die ursprüngliche Annahme, dass infektiöse luftgetragene Tröpfchenkerne einen Durchmesser von $\leq 5 \mu \mathrm{m}$ haben [25], gilt für die Tuberkulose. Unklar ist zurzeit aber, ob sie generell auch für andere aerogen übertragene Infektionskrankheiten zutrifft [6].

Nur wenige Infektionskrankheiten. Die aerogene Übertragbarkeit ist mit ausreichender Sicherheit nur für Tuberkulose, Masern und Varizellen (Windpocken und disseminierter Herpes zoster) beschrieben $[6,9,15]$. Andere respiratorische Erreger verlieren in austrocknenden Tröpfchen unter Einwirkung von Stressfaktoren wie Temperaturabfall, Austrocknung, Licht und UVStrahlung offenbar rasch ihre Infektionsfähigkeit [29]. Historische Daten lassen vermuten, dass auch die Pocken unter ungewöhnlichen Bedingungen aerogen übertragbar waren. Der übliche Übertragungsweg scheint jedoch auch hier die Tröpfchenübertragung gewesen zu sein [6].

Aerogen übertragen werden nachweislich nur die Tuberkulose, Masern und Varizellen. Bei wenigen anderen Erregern (z. B. Pocken, Affenpocken, SARS) scheint die aerogene Übertragung unter bestimmten Umständen möglich zu sein bzw. ist sie aufgrund unzureichender epidemiologischer Daten nicht auszuschließen.

Scharfe Abgrenzung zur Tröpfchenübertragung? Einige Beobachtungen haben die Frage aufgeworfen, wie scharf sich die aerogene Übertragung von der Tröpfchenübertragung abgrenzen lässt. Für einige Erreger wie SARS- , Influenza- und Rhinoviren sowie für intes- tinale Erreger wie Noro- und Rotaviren wurde unter experimentellen, z.T. auch unter natürlichen Bedingungen eine Übertragung mit Aerosolen beschrieben [24,36 - 41]. In einigen Fällen wurden hier zwar Übertragungswege von $>1 \mathrm{~m}$ beobachtet, diese fanden aber innerhalb klar umgrenzter Räume statt, z.B. in einem Patientenzimmer. Möglicherweise hängen diese Beobachtungen mit dem Phänomen zusammen, dass auch Partikel mit einer Größe von bis zu $100 \mu \mathrm{m}$ in der Luft suspendiert bleiben können, wenn die Luftgeschwindigkeit die terminale Sedimentationsgeschwindigkeit der Partikel übersteigt [35]. Insgesamt ist nicht davon auszugehen, dass die genannten Erreger lange infektiös bleiben und lange Strecken mit dem Luftstrom zurücklegen können. Schutzmaßnahmen, wie sie für aerogen übertragbare Erreger indiziert sind, werden gegen diese Erreger daher unter normalen Umständen nicht empfohlen [6,7].

Obligat, bevorzugt oder opportunistisch. Nach Analyse von Beschreibungen der Übertragungswege von SARS haben Roy und Milton eine neue Klassifikation der aerogenen Übertragung vorgeschlagen [42]:

- Obligat aerogene Übertragung: Unter natürlichen Bedingungen erfolgt die Übertragung nur durch Inhalation von Aerosolen aus kleinen Schwebeteilchen (z. B. Tuberkulose).

- Bevorzugt aerogene Übertragung: Unter natürlichen Bedingungen können Infektionen auf mehreren Wegen übertragen werden, die aerogene Übertragung ist aber der vorherrschende Weg (z.B. Masern, Varizellen).

- Opportunistisch aerogene Übertragung: Unter natürlichen Bedingungen werden die Erreger auf anderen Wegen übertragen, unter besonderen Umständen ist aber auch eine Übertragung mit Aerosolen aus kleinen Schwebeteilchen möglich.

Aerosol-erzeugende Maßnahmen. Das Konzept der opportunistisch aerogenen Übertragung mag eine Erklärung für die seltenen Fälle einer aerogenen Übertragung von Erregern wie Pocken-, SARS-, Influenzaund Noroviren liefern, die normalerweise auf anderen Wegen übertragen werden. Die WHO hat das Konzept aufgegriffen und fordert Maßnahmen zum Schutz vor aerogener Übertragung, sobald bei Patienten mit schweren Infektionskrankheiten, deren Übertragungswege nicht vollständig aufgeklärt sind, „Aerosolerzeugende Maßnahmen“ (engl.: aerosol-generating procedures) durchgeführt werden [7]. So empfiehlt die WHO bei Krankheiten wie, SARS, MERS (Middle East Respiratory Syndrome), Ebolavirus-Krankheit sowie saisonaler und pandemischer Influenza normalerweise 
eine Maßnahmenkombination zum Schutz vor Kontaktübertragung (contact precautions) und Tröpfchenübertragung (droplet precautions); bei Aerosolerzeugenden Maßnahmen empfiehlt sie dagegen einen Schutz vor Kontakt- und aerogener Übertragung (airborne precautions) $[7,43,44]$.

\section{Checkliste}

Aerosol-erzeugende Maßnahmen

Folgende Aerosol-erzeugenden Maßnahmen erwiesen sich in einer Metaanalyse [45] als signifikantes Infektionsrisiko:

- Intubation (OR: 6,6; Cl: 2,3 - 18,9 bzw. $\mathrm{Cl}: 4,1-10,6)$

- Tracheotomie (OR: 4,2; Cl: 1,5-11,5)

- nicht-invasive Beatmung (OR: 3,1; Cl: 1,4-6,8)

- manuelle Beatmung vor Intubation (OR: 2,8; Cl: 1,3-6,4)

$\mathrm{OR}=$ odss ratio, $\mathrm{Cl}=$ Konfidenzintervall

Für Maßnahmen wie endotracheale Absaugung, Bronchoskopie, Absaugen von Körperflüssigkeiten, Medikamentenverneblung, $\mathrm{O}_{2}$-Verabreichung, erhöhtem $\mathrm{O}_{2}$-Flow, Manipulationen an $\mathrm{O}_{2}$-und BiPAPMasken, Defibrillation, Thoraxkompression, Einführung einer Magensonde und Sputum-Gewinnung ließen sich keine signifikanten Infektionsrisiken nachweisen [45]. Es erscheint aber sinnvoll, weitere Untersuchungen zur Definition „Aerosol-erzeugender Maßnahmen“ durchzuführen [7].

\section{Maßnahmen zur Prävention der aerogenen Übertragung von Mensch zu Mensch}

Maßnahmen zur Prävention der aerogenen Übertragung zielen prinzipiell darauf $a b$,

- die Emission infektiöser Tröpfchenkerne in die Atemluft von empfänglichen Personen möglichst zu verhindern,

- die Verbreitung infektiöser Tröpfchenkerne im Innenraumbereich möglichst zu verhindern (in Außenbereichen findet rasch eine Verdünnung zu unbedenklichen Konzentrationen statt) und

- die Inhalation infektiöser Tröpfchenkerne in der Raumluft durch empfängliche Personen, die sich gemeinsam mit einem infektiösen Patienten im selben Raum befinden, möglichst zu verhindern.
Standard-/Basishygiene. Eine der Komponenten der bei allen Patienten zu beachtenden Standard Precautions ist das richtige Verhalten beim Husten, Niesen und Schnäuzen (engl.: respiratory hygiene, cough etiquette) $[6,10]$. Gefordert wird hier, dass Patienten und Personal mit Zeichen einer Atemwegsinfektion in ein Einmaltuch husten/niesen/schnäuzen, dieses entsorgen und sich anschließend die Hände desinfizieren oder waschen. Die Forderungen basieren auf Erfahrungen im Rahmen neuer respiratorischer Infektionen wie SARS und Vogelgrippe und zielen darauf ab, die Abgabe respiratorischer Erreger mit Händen, Tröpfchen und Tröpfchenkernen in die Umgebung zu verringern.

\section{Tipp für die Praxis}

Der Effekt der „Cough Etiquette“ zur Prävention aerogen übertragbarer Infektionskrankheiten ist bisher nicht gut belegt. Auf keinen Fall ist von dieser Maßnahme ein sicherer Schutz vor der nosokomialen Transmission aerogen übertragener Infektionen zu erwarten; bei der Versorgung von Patienten mit aerogen übertragbaren Infektionskrankheiten ist sie daher durch zusätzliche Schutzmaßnahmen zu ergänzen.

Flächen- und Händedesinfektion ineffektiv. Auch die Reinigung und Desinfektion häufig berührter Oberflächen der Patientenumgebung zählen zu den Standard Precautions $[6,10]$. Obwohl es generell wichtig ist, diese Maßnahme im Sinne der Standard- oder Basishygiene routinemäßig bei allen Patienten umzusetzen, ist von ihnen bei der Prävention aerogen übertragbarer Infektionen kein entscheidender Effekt zu erwarten. Eintrittspforte aerogen übertragbarer Erreger sind die tieferen Atemwege, und zumindest für die Tuberkulose ist bekannt, dass sie nicht von kontaminierten Oberflächen übertragen wird, da eine relevante Re-Aerosolisierung in der Praxis nicht vorkommt $[46,47]$.

Die Flächendesinfektion mit „tuberkuloziden“

Präparaten ist bei der Prävention der Tuberkulo-

seübertragung irrelevant [46].

Aus ähnlichen Gründen ist die (sonst so wichtige) Händedesinfektion bei der Prävention der aerogenen Übertragung nosokomialer Infektionen nur von untergeordneter Bedeutung.

\section{Raumlufttechnik, Atemschutzmasken und Mund-}

Nasen-Schutz. Als effektivste Maßnahmen zur Prävention der nosokomialen Übertragung aerogen übertragener Infektionen gelten die Unterbringung infektiöser 
Patienten in einem Isolierzimmer mit geeigneter Raumlufttechnik sowie der richtige Gebrauch von Atemschutzmasken und Mund-Nasen-Schutz gemäß folgender Prinzipien $[6,7,9,11,15]$ :

- Die Unterbringung von Patienten mit infektiösen, aerogen übertragenen Infektionskrankheiten (insbesondere Tuberkulose, Masern, Pocken, Windpocken, disseminierter Herpes zoster) in einem lüftungstechnisch ausgestatteten Raum mit relativem Luftunterdruck zu den angrenzenden Räumen und mindestens 12-fachem Luftwechsel pro Stunde wird in der aktuellen amerikanischen Isolierungs-Leitlinie empfohlen [6]. Als Alternative nennt das Deutsche Zentralkomitee zur Bekämpfung der Tuberkulose (DZK) die natürliche Fensterlüftung, vorzugsweise in einem Zimmer mit Vorraum [47]. Obwohl nicht durch klinische Beobachtungen oder Studien belegt, erscheint auch diese Alternative als plausibel.
Wichtig ist bei der aerosolen Infektisolierung, dass während des Patientenaufenthalts in Isolierzimmern die Türen geschlossen bleiben.

- Mit einer Atemschutzmaske mindestens der Kategorie FFP2 (gem. Euronorm DINEN 149) bzw. N95 (gem. $\mathrm{NIOSH}=$ National Institute for Occupational Safety and Health: US-amerikanische Bundesbehörde für Arbeitssicherheit) schützen sich andere Personen (z.B. Personal, Angehörige) in einem Raum, in dem sich ein Patient mit einer infektiösen, aerogen übertragenen Infektionskrankheit aufhält. Dicht anliegende Atemschutzmasken verfügen über eine definierte Filterfunktion und eignen sich zur Elimination infektiöser Tröpfchenkerne aus der inspirierten Atemluft (s. Kasten „Atemschutzmasken“).

- Einen Mund-Nasen-Schutz tragen Patienten mit einer infektiösen, aerogen übertragenen Infektionskrankheit außerhalb ihres Isolierzimmers in Räumen, die von anderen Personen frequentiert werden.

\section{Hintergrundwissen}

\section{Atemschutzmasken}

Als „Atemschutzmasken“ (engl.: respirators oder particulate respirators) werden in der Medizin oft partikelfiltrierende Halbmasken (Synonym „Feinstaubmasken“, FFP-Masken, engl.: filtering face pieces,) bezeichnet. Diese Atemschutzgeräte haben die Aufgabe, den Träger vor der Inhalation kleiner, unsichtbarer, in der Luft suspendierter Schwebeteilchen (z. B. Tröpfchenkerne) zu schützen. Sofern diese Schwebeteilchen infektiöse Erreger enthalten, schützen sie vor deren aerogener Übertragung.

Atemschutzmasken bestehen aus schwebstofffiltrierendem Material (meist Vliesstoff), welches die Luft passieren muss, bevor sie inhaliert wird. Um zu verhindern, dass die eingeatmete Luft als „Leckage“ zwischen Maskenrand und Haut ungefiltert vorbei strömt, müssen Atemschutzmasken (insbes. der Nasenbügel) der Anatomie des Mund-Nasen-Bereichs angepasst werden und dort möglichst luftdicht mit der Haut abschließen. Dazu werden sie meist durch Gummizüge fixiert, die um den Hinterkopf gelegt werden. Barthaare können den Dichtsitz beeinträchtigen, Männer sollten daher im
Kontaktbereich mit dem Maskenrand glatt rasiert sein.

Zu Zwecken des Infektionsschutzes werden Atemschutzmasken in Räumen (insb. Isolierzimmern) getragen, in denen sich ein Patient mit einer infektiösen, aerogen übertragenen Infektionskrankheit aufhält. Der Patient selbst braucht keine Atemschutzmaske zu tragen, um andere Personen zu schützen; zu diesem Zweck trägt er vielmehr einen Mund-Nasen-Schutz [6, $46,47]$. Unsinnig wäre es, einen solchen Patienten mit einer Atemschutzmaske mit Ausatemventil auszustatten, durch das die Luft ungefiltert ausströmt.

Partikelfiltrierende Halbmasken werden in Europa nach DINEN 149 geprüft und in die Geräteklassen FFP1, FFP2 und FFP3 eingeteilt. Von Bedeutung für den Schutz vor aerogen übertragbaren Infektionen sind nur die Klassen FFP2 und FFP3 [7], wobei die Filter der FFP2-Masken über einen Abscheidegrad von 95\% und der FFP3Masken von 99,7\% verfügen [7], entsprechend einer gesamten, nach innen gerichteten Leckage (Gesamtleckage) von 8 bzw. $2 \%$ [50]. In den USA werden Atemschutzmasken gemäß NIOSH-Standard in die Klassen N95, N99 und N100 eingeteilt, entsprechend einem Abscheidegrad von 95, 99 bzw. 99,97\% [6, 7, 11]. (Der Abscheidegrad gibt den Anteil von Partikeln der Größe von 0,3 $\mu \mathrm{m}$ an, die von den Filtern unter standardisierten Bedingungen aus der Atemluft abgeschieden werden).

Atemschutzmasken weisen einen gewissen Atemwiderstand auf und sind in Deutschland meist Atemschutzgeräten der Gruppe 1 zuzuordnen, deren Trägern gemäß Verordnung zur arbeitsmedizinischen Vorsorge (ArbMedVV) eine arbeitsmedizinische Vorsorge anzubieten ist. Im Einzelfall können sie jedoch auch der Gruppe 2 zugeordnet werden, z. B. wenn mit FFP3-Masken körperlich schwer gearbeitet wird oder ungünstige klimatische Verhältnisse vorliegen. In diesen Fällen ist eine arbeitsmedizinische Vorsorge gem. ArbMedVV Pflicht [50]. Um den Atemwiderstand zumindest beim Ausatmen zu reduzieren, werden Atemschutzmasken teilweise mit einem Ausatemventil angeboten, durch das die ausgeatmete Luft ungefiltert ausströmen kann. 
Aerogene Infektionsisolierung (AlI). Bei stationärer Unterbringung von Patienten mit klinisch/epidemiologisch relevanten Infektionen, die aerogen übertragen werden, wird zum Schutz von Mitpatienten, Besuchern und Personal eine aerogene Infektionsisolierung gefordert (Abkürzung: AII, kurz: aerogene Isolierung, engl.: airborne precautions, airborne isolation). Ähnlich wie bei der Kontakt- und Tröpfchenisolierung (s.o.) ist auch bei der AII die Standard-/Basishygiene (Standard Precautions) immer zu beachten. Für die Dauer der Infektiosität umfasst die AII darüber hinaus im Wesentlichen folgende Maßnahmen [6, 7,9,11,15,18,44,47]:

- Unterbringung in einem Isolierzimmer mit o.g. raumlufttechnischer Ausstattung (Luftunterdruck, mindestens 12-facher Luftwechsel pro Stunde) oder zumindest gem. DZK-Vorgabe in einem Zimmer mit Fensterlüftung, ggf. mit Vorraum [47]. Die Türen des Zimmers müssen geschlossen bleiben. Eine Kohortenisolierung mehrerer Patienten mit gleichem Erreger ist prinzipiell möglich, wegen des Risikos von Superinfektionen nicht jedoch bei der Tuberkulose.

- Bei Betreten des Isolierzimmers legen Personal und Besucher eine Atemschutzmaske mindestens der Kategorie FFP2 (oder N95) an. Das DZK empfiehlt, dass infektiöse Tuberkulosepatienten einen MundNasen-Schutz tragen, wenn sich in ihrem Isolierzimmer Personal oder Besucher aufhalten [47]. Gemäß aktueller Isolierungs-Leitlinie der CDC [6] gilt es als ungeklärte Frage, ob sich empfängliches Personal im Isolierzimmer von Patienten mit Masern und Varizel- len mit einem Mund-Nasen-Schutz oder einer Atemschutzmaske schützen sollten [6].

- Die Isolierzimmer von Patienten mit Masern und Varizellen sollten möglichst nur von immunem Personal (IgG-Titer!) betreten werden.

- Der isolierte Patient verlässt das Zimmer nur in begründeten Ausnahmefällen und in Absprache mit dem Personal. Außerhalb des Isolierzimmers trägt der Patient einen Mund-Nasen-Schutz.

Die Isolierungs-Leitlinie der CDC enthält als Appendix A eine alphabetische Liste von Infektionskrankheiten und Erregern, in der aufgrund klinisch-epidemiologischer Daten vermerkt ist, in welchen Fällen die Standard Precautions ausreichen und in welchen diese mit übertragungsspezifischen Isolierungsmaßnahmen wie der AII kombiniert werden müssen [6]. Die Infektionskrankheiten, die bei Nachweis oder begründetem Verdacht für die Dauer der Infektiosität eine AII erforderlich machen, umfassen in dieser Liste (z.T. in Kombination mit anderen übertragungsspezifischen Isolierungsmaßnahmen):

- Lungen- und Kehlkopf-Tuberkulose

- sezernierende extrapulmonale Formen der Tuberkulose

- Masern

- Pocken

- Affenpocken

- SARS

- Varizellen

- disseminierter Herpes zoster

\section{Hintergrundwissen}

Sonderweg des deutschen Arbeitsschutzes

Die sich selbst als „Stand der Technik, Arbeitsmedizin und Arbeitshygiene“ deklarierenden Technischen Regeln für Biologische Arbeitsstoffe - TRBA 250 [50] kennen nicht den Unterschied zwischen der aerogenen und der Tröpfchenübertragung, wie er sich anhand der wissenschaftlichen Fachliteratur als Stand der Wissenschaft darstellt und wie er von Institutionen wie der Weltgesundheitsorganisation (WHO), den Centers for Disease Control and Prevention (CDC) sowie der Occupational Safety and Health Administration (OSHA) vertreten wird. Dies führt zu verwirrenden Aussagen über die generelle Luftübertragbarkeit von respi- ratorischen Erregern (z. B. saisonale Influenza-Viren, Corynebacterium diphtheriae, Streptococcus pyogenes, Haemophilus spp.) und von Erregern, die im Erbrochenen vorkommen (z. B. Noro- und Rotaviren), sowie zu der Forderung, bei Tätigkeiten in der Nähe entsprechend infizierter Patienten generell mindestens eine FFP2-Maske zu tragen.

Von Bedeutung ist in diesem Zusammenhang folgende Aussage in Ziffer 4.2.6, Absatz 2 der TRBA 250: „Die PSA ist auf der Grundlage des Ergebnisses der Gefährdungsbeurteilung auszuwählen. Die Beschäftigten sind bei der Auswahl der
PSA in geeigneter Weise zu beteiligen. Der Einsatz belastender PSA ist auf das unbedingt erforderliche Maß zu beschränken und darf keine Dauermaßnahme sein.“ Führt man aber eine wissenschaftlich fundierte Gefährdungsbeurteilung durch, so stellt man fest, dass Erreger wie C. diphtheriae, S. pyogenes, Haemophilus spp., Noro-, Rota- und saisonale InfluenzaViren in der klinischen Praxis so gut wie nie aerogen übertragen werden und dass in diesen Fällen das Tragen teurer und belastender FFP2 - oder gar FFP3-Masken nicht indiziert ist. 


\section{Kernaussagen}

- Infektionskrankheiten werden auf verschiedenen Wegen übertragen und der Übertragungsweg entscheidet über die Wahl der wirksamen Schutzmaßnahmen.

- Allgemein lassen sich direkte und indirekte Übertragungswege unterscheiden.

- Nosokomiale Infektionen werden überwiegend von Mensch zu Mensch übertragen; wesentliche Übertragungswege sind die direkte und indirekte Kontaktübertragung, die Tröpfchenübertragung und die aerogene Übertragung.

- Die Tröpfchenübertragung ist eine Form der direkten Kontaktübertragung und unterscheidet sich sowohl bezüglich des Übertragungsmechanismus als auch bezüglich der effektiven Präventionsmaßnahmen grundlegend von der aerogenen Übertragung.

- Durch konsequente Umsetzung der Standard Precautions (= Standard- oder Basishygiene) lassen sich in der Praxis viele Fälle der Kontakt- und Tröpfchenübertragung vermeiden. Die aerogene Übertragung erfordert dagegen meist spezielle Präventionsmaßnahmen unter Verwendung schwebstofffiltrierender Atemschutzmasken und spezieller Raumlufttechnik.
- Bei Auftreten leicht übertragbarer, klinisch und epidemiologisch relevanter Infektionskrankheiten, besonders aber in Ausbruchssituationen, sind übertragungsspezifische Isolierungsmaßnahmen indiziert, die nach dem jeweiligen Übertragungsweg als Kontaktisolierung, Tröpfchenisolierung oder aerogene Infektionsisolierung bezeichnet werden.

- Unkenntnisse über die spezifischen Übertragungswege der verschiedenen Infektionskrankheiten können nicht nur zu Ressourcenverschwendung führen, sondern auch zur Gefährdung von Patienten, medizinischem Personal und der Öffentlichkeit.
Der „Ebola-Effekt“. Befürchtungen im Zusammenhang mit den nicht vollständig aufgeklärten Übertragungswegen von schweren, seltenen, nicht-therapierbaren Infektionskrankheiten führen - besonders unter dem Druck der Öffentlichkeit - leicht zu unverhältnismäßig aufwändigen Präventionsstrategien [6]. So nennen die CDC in ihrer aktuellen Isolierungs-Leitlinie die Kontakt- und Tröpfchenübertragung als einzige relevante Übertragungswege viraler hämorrhagischer Fieber wie Lassa-, Ebola- und Marburgfieber [6]. Konsequenterweise empfahlen die CDC bei diesen Erkrankungen ursprünglich eine Kombination aus Standard Precautions, Kontakt- und Tröpfchenisolierung, den Gebrauch von N95-Atemschutzmasken dagegen nur bei aerosolerzeugenden Maßnahmen. In den aktuell im Internet verfügbaren CDC-Angaben werden diese Übertragungswege bestätigt, gleichzeitig wird aber bei der Versorgung von Patienten mit Ebolavirus-Krankheit das generelle Tragen mindestens von N95-Masken gefordert [48].

Auch das Robert-Koch-Institut empfiehlt bei der Versorgung von Patienten mit Ebolavirus-Krankheit zurzeit generell den Gebrauch von FFP3-Atemschutzmasken oder anderen Vorrichtungen zur Schwebstofffilterung der Atemluft, z.T. sogar in Kombination mit Schutzanzügen, obwohl es in derselben Mitteilung heißt, dass Ebolaviren durch Kontakt und Tröpfchen, nicht jedoch durch die Luft übertragen werden [49].

\section{Mit dem Rückgang der aktuellen Ebola-Epidemie in} Westafrika sowie zunehmenden Erfahrungen und epidemiologischen Erkenntnissen über die tatsächlichen Übertragungswege ist zu hoffen, dass solche Tenden- zen wieder rückgängig gemacht und die Schutzmaßnahmen auf ein vernünftiges Maß reduziert werden.

Interessenkonflikt: Der Autor gibt an, dass kein Interessenkonflikt im Zusammenhang mit dieser Publikation besteht.

\section{Über den Autor}

\section{Roland Schulze-Röbbecke}

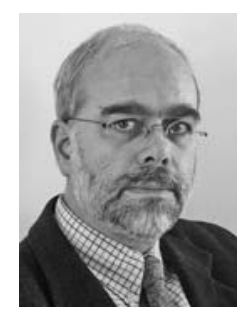

PD Dr. med. Jahrgang 1954. Studium der Agrarwissenschaften und Medizin an den Universitäten Bonn, Freiburg und Toulouse. Seine Laufbahn führte ihn vom Hygiene-Institut der Universität Bonn über das Institut für Hygiene und Umweltmedizin der RWTH Aachen, den Service d' Études et de Recherches Environnement et Santé der Universität Nancy zum Institut für Hygiene und zum Institut für Medizinische Mikrobiologie und Krankenhaushygiene des Universitätsklinikums Düsseldorf. Er ist Krankenhaushygieniker des Universitätsklinikums Düsseldorf.

\section{Korrespondenzadresse}

Priv.-Doz. Dr. med. Roland Schulze-Röbbecke Universitätsklinikum Düsseldorf Institut für Medizinische Mikrobiologie und Krankenhaushygiene

Universitätsstraße 1

40225 Düsseldorf

E-Mail: Schulzrr@uni-duesseldorf.de 


\section{Literatur}

1 Silvestri L, Monti Bragadin C, Milanese M et al. Are most ICU infections really nosocomial? A prospective observational cohort study in mechanically ventilated patients J Hosp Infect 1999; 42: 125 - 133

2 Kommission für Krankenhaushygiene und Infektionsprävention beim Robert-Koch-Institut. Prävention postoperativer Infektionen im Operationsgebiet. Bundesgesundheitsbl 2007; 50: $377-393$

3 Morgan DJ, Kaye KS, Diekema DJ. Reconsidering isolation precautions for endemic methicillin-resistant staphylococcus aureus and vancomycin-resistant enterococcus. J Am Med Assoc 2014; 312: 1395 - 1396

4 Osterholm MT, Hedberg CW. Epidemiologic principles. In: Mandell GL, Bennett JE, Dolin R, eds. Principles and Practice of Infectious Diseases. 7th: ed. Philadelphia, Churchill Livingsone: Elsevier; 2010

5 Schulze-Röbbecke R, Hauer T. Ausbruchsmanagement in medizinischen Einrichtungen. Krankenhaushygiene up2date 2013; 8: 165-183

6 Siegel JD, Rhinehart E, Jackson M et al. Guideline for isolation precautions: preventing transmis-sion of infectious agents in healthcare settings 2007. Am J Infect Control 2007; 35: 65 S164 http://www.cdc.gov/hicpac/2007ip/2007isolationprecautions.html

7 World Health Organization. Infection prevention and control of epidemic- and pandemic-prone acute respiratory infections in health care. Genève: World Health Organization; 2014: http://apps.who.int/iris/bitstream/10665/112656/1/ 9789241507134_eng.pdf?ua=1

8 Blatt SP, Parkinson MD, Pace E et al. Nosocomial Legionnaires' Disease: Aspiration as a primary mode of disease acquisition. Am J Med 1993; 95: 16-22

9 Beekman SE, Henderson DK. Controversies in isolation policies and practices. In: Wen-zel RP, ed. Prevention and Control of Nosocomial Infections. 3rd: ed. Baltimore: William \& Wilkins; 1997

10 Schulze-Röbbecke R. Standardmaßnahmen zur Prävention der Übertragung nosokomialer Infektionen - Standardhygiene, Basishygiene. Krankenhaushygiene up2date 2009; 4: 193 205

11 Occupational Safety and Health Administration. Pandemic Influenza Preparedness and Response Guidance for Healthcare Workers and Healthcare Employers. OSHA document 3328 05. 2007: https://www.osha.gov/Publications/3328-052007-English.html

12 Kommission für Krankenhaushygiene und Infektionsprävention beim Robert-Koch-Institut. Infektionsprävention in Heimen. Bundesgesundheitsbl 2005; 48: 1061 - 1080

13 Kommission für Krankenhaushygiene und Infektionsprävention beim Robert-Koch-Institut. Anforderungen an die Hygiene bei der medizinischen Versorgung von immun-supprimierten Patienten. Bundesgesundheitsbl 2010; 53: 357 - 388

14 Kommission für Krankenhaushygiene und Infektionsprävention beim Robert-Koch-Institut. Hygienemaßnahmen bei Infektionen oder Besiedlung mit multiresistenten gramnegativen Stäbchen. Bundesgesundheitsbl 2012; 55: 1311 -1354
15 Edmond MB, Wenzel RP. Isolation. In: Mandell GL, Bennett JE, Dolin R eds. Principles and Practice of Infectious Diseases 7th ed. Philadelphia: Churchill Livingsone Elsevier; 2010

16 Fätkenheuer G, Hirschel B, Harbarth S. Screening and isolation to control meticillin-resistant Staphylococcus aureus: sense, nonsense, and evidence. Lancet 2014: DOI 10.1016/S01406736(14)60660-7

17 Schulze-Röbbecke R. Isolierung von MRSA-Patienten: Wie lange noch? Krankenhaushygiene up2date 2013; 8: 81-82

18 Schulze-Röbbecke R. Isolierung infektiöser Patienten - auf die Übertragungswege kommt es an. Krankenhaushygiene up2date 2006; 1: 97 - 117

19 Eyre DW, Griffiths D, Vaughan A et al. Asymptomatic Clostridium difficile colonisation and onward transmission. PLoS One 2013; 8: e78445

20 Bassinet L, Matrat M, Njamkepo E et al. Nosocomial pertussis outbreak among adult patients and healthcare workers. Infect Control Hosp Epidemiol 2004; 25: 995 - 997

21 Wong TW, Lee CK, Tam W et al. Cluster of SARS among medical students exposed to single patient, Hong Kong. Emerg Infect Dis 2004; 10: 269-276

22 Pachucki CT, Pappas SA, Fuller GF et al. Influenza A among hospital personnel and patients. Implications for recognition, prevention, and control. Arch Intern Med 1989; 149: 77 - 80

23 Feigin RD, Baker CJ, Herwaldt LA et al. Epidemic meningococcal disease in an elemen-tary-school classroom. N Engl J Med 1982; 307: $1255-1257$

24 Dick EC, Jennings LC, Mink KA et al. Aerosol transmission of rhinovirus colds. J Infect Dis 1987; 156: $442-448$

25 Duguid JP. The size and duration of air-carriage of respiratory droplets and droplet nuclei. J Hyg (Lond) 1946; 44: 471 -479

26 Papineni RS, Rosenthal FS. The size distribution of droplets in the exhaled breath of healthy human subjects. J Aerosol Med 1997; 10: $105-116$

27 Xie X, Li Y, Chwang ATY et al. How far droplets can move in indoor environments - revisiting the Wells evaporation-falling curve. Indoor Air 2007; 17: 211 - 225

28 Wells WF. On air-borne infection. Study II. Droplets and droplet nuclei. Am J Hyg 1934; 20: 611-618

29 Tang JW. The effect of environmental parameters on the survival of airborne infectious agents. J R Soc Interface 2009; 6: 737 - S746

30 Yang W, Elankumaran S, Marr LC. Concentrations and size distributions of airborne influenza $A$ viruses measured indoors at a health centre, a day-care centre, and on aeroplanes. J $R$ Soc Interface 2011; 8: 1176-1184

31 Blachere FM, Lindsley WG, Pearce TA et al. Measurement of airborne influenza virus in a hospital emergency department. Clin Infect Dis 2009; 48: 438-440

32 Hall CB, Douglas RGJr, Schnabel KC et al. Infectivity of respiratory syncytial virus by various routes of inoculation. Infect Immun 1981; 33: 779-783

33 Downie AW, Meiklejohn M, St Vincent L et al. The recovery of smallpox virus from patients and their environment in a smallpox hospital. Bull World Health Organ 1965; 33: 615 622

34 Occupational Safety and Health Administration. OSHA Fact Sheet "Respiratory Infection Control: Respirators Versus Surgical Masks". https://www.osha.gov/Publications/respiratorsvs-surgicalmasks-factsheet.html (letzter Zugriff: 8.11.2014) 
35 Cole EC, Cook CE. Characterization of infectious aerosols in health care facilities: an aid to effective engineering controls and preventive strategies. Am J Infect Control 1998; 26: 453 464

36 Olsen SJ, Chang HL, Cheung TY et al. Transmission of the severe acute respiratory syndrome on aircraft. N Engl J Med 2003; 349: 2416 - 2422

37 Yu IT, Li Y, Wong TW et al. Evidence of airborne transmission of the severe acute respiratory syndrome virus. N Engl J Med 2004; 350: 1731 - 1739

38 Moser MR, Bender TR, Margolis HS et al. An outbreak of influenza aboard a commercial airliner. Am J Epidemiol 1979; 110: $1-6$

39 Alford RH, Kasel JA, Gerone PJ et al. Human influenza resulting from aerosol inhalation. Proc Soc Exp Biol Med 1966; 122: $800-804$

40 Chadwick PR, McCann R. Transmission of a small round structured virus by vomiting during a hospital outbreak of gastroenteritis. J Hosp Infect 1994; 26: 251 - 259

41 Prince DS, Astry C, Vonderfecht S et al. Aerosol transmission of experimental rotavirus infection. Pediatr Infect Dis 1986; 5 : $218-222$

42 Roy C], Milton DK. Airborne transmission of communicable infection - the elusive pathway. N Engl J Med 2004; 350: $1710-1712$

43 World Health Organization. Infection prevention and control during health care for probable or confirmed cases of novel coronavirus (nCoV) infection. 2013: http://www.who.int/csr/ disease/coronavirus_infections/IPCnCoVguidance_06May13. pdf?ua=1 (letzter Zugriff: 10.11.2014)
44 World Health Organization. Interim Infection Prevention and Control Guidance for Care of Patients with Suspected or Confirmed Filovirus Haemorrhagic Fever in Health-Care Settings, with Focus on Ebola. 2014: http://apps.who.int/iris/bitstream/10665/130596/1/WHO_HIS_SDS_2014.4_eng.pdf? ua=1\&ua=1\&ua=1 (letzter Zugriff: 10.11.2014)

45 Tran K, Cimon K, Severn M et al. Aerosol generating procedures and risk of transmission of acute respiratory infections to healthcare workers: a systematic review. PLoS One 2012; 7: e35797

46 Centers for Disease Control and Prevention. Guidelines for Preventing the Transmission of Mycobacterium tuberculosis in Health-Care Settings, 2005. MMWR 2005; 54: (No. RR-17)

47 Ziegler R, Just H-M, Castell S et al. Infektionsprävention bei Tuberkulose: Empfehlungen des DZK. Pneumologie 2012; 66: $269-282$

48 Centers for Disease Control and Prevention. Guidance on Personal Protective Equipment To Be Used by Healthcare Workers During Management of Patients with Ebola Virus Disease in U. S. Hospitals, Including Procedures for Putting On (Donning) and Removing (Doffing). 2014: http://www.cdc.gov/vhf/ebola/hcp/procedures-for-ppe.html (letzter Zugriff: 10.11.2014)

49 Robert-Koch-Institut. Übersicht Ebolafieber. 31. 10 2014: Stand: http://www.rki.de/DE/Content/InfAZ/E/Ebola/Uebersicht.html\#doc5045280bodyText20 (letzter Zugriff: 10.11.2014)

50 Ausschuss für Biologische Arbeitsstoffe (ABAS). Technische Regeln für Biologische Arbeitsstoffe - Biologische Arbeitsstoffe im Gesundheitswesen und in der Wohlfahrtspflege TRBA 250. Gemeinsames Ministerialblatt 2014: Nr. 10/11 vom 27.3.2014 


\section{CME-Fragen}

\section{CME•thieme.de}

CME-Teilnahme

- Viel Erfolg bei Ihrer CME-Teilnahme unter http://cme.thieme.de

- Diese Fortbildungseinheit ist 12 Monate online für eine CME-Teilnahme verfügbar.

- Sollten Sie Fragen zur Online-Teilnahme haben, unter http://cme.thieme.de/hilfe finden Sie eine ausführliche Anleitung.
Wie kann sich das Personal bei Betreuung eines Patienten mit infektiöser Lungentuberkulose am besten vor einer Infektion schützen?

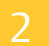

Welcher Erreger wird nicht durch Tröpfchen übertragen?

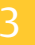

Welche Aussage trifft zu?
A durch Erhöhung der Händedesinfektions-Compliance
B durch das Tragen einer FFP2-Atemschutzmaske
C durch das Tragen eines Mund-Nasen-Schutzes
D durch das Tragen von Schutzhandschuhen
E durch Flächendesinfektion mit tuberkuloziden Präparaten
A Parvovirus B19
B Influenzaviren
C Meningokokken
D Plasmodium falciparum
E Mycoplasma pneumoniae

Wie lässt sich bei einem Patienten mit Meningokokken-Meningitis die Übertragung der Erreger am besten verhindern?

Welche Infektionskrankheit bzw. Erreger werden nicht überwiegend durch Kontakt übertragen?
A Beim Erbrechen entstehen immer sowohl Tröpfchen als auch Tröpfchenkerne; in Anwesenheit eines sich übergebenden Patienten ist daher immer eine FFP2-Maske zu tragen.

B Obwohl beim Erbrechen sowohl Tröpfchen als auch Tröpfchenkerne entstehen, kommen dabei aufgrund des niedrigen $\mathrm{pH}$-Werts des Erbrochenen keine Übertragungen vor.

C Beim Husten und Niesen entstehen immer sowohl Tröpfchen als auch Tröpfchenkerne; bei allen respiratorischen Krankheitserregern ist daher von der aerogenen Übertragbarkeit auszugehen.

D Obwohl beim Husten und Niesen immer sowohl Tröpfchen als auch Tröpfchenkerne entstehen, sind nur wenige respiratorische Krankheitserreger aerogen übertragbar.

E Die beim Husten und Niesen entstehenden Tröpfchenkerne bewegen sich schneller durch die Luft als die dabei entstehenden Tröpfchen; diese verursachen daher überwiegend Late-OnsetPneumonien, jene dagegen Early-Onset-Pneumonien.
A durch Tragen eines Mund-Nasen-Schutzes im Umkreis von $1 \mathrm{~m}$ um den Patienten

B durch Tragen von Schutzhandschuhen und Schutzkittel im gesamten Patientenzimmer

C durch konsequente Umsetzung der WHO-Indikationen zur Händedesinfektion

D durch Unterbringung des Patienten in einem Zimmer mit Luftunterdruck

E durch Unterbringung des Patienten in einem Zimmer mit Vorraum und häufiger Fensterlüftung
A Ebolaviren
B Noroviren
C Scabies
D Clostridium difficile
E Varizellen 


\section{CME-Fragen}

Übertragung nosokomialer Infektionen und Prinzipien der Transmissionsprävention

6

Welche Aussage ist richtig?

7

Welcher der genannten Erreger wird typischerweise durch direkten Kontakt übertragen?

8

Auf welchem Wege werden nosokomiale Infektionen am häufigsten übertragen?

9

Welcher der genannten Erreger wird durch Luft übertragen?

\section{0}

Welche der nachfolgend genannten Maßnahmen eignet sich am besten, um bei der stationären Patientenversorgung die Übertragung von MRSA zu vermeiden?
A Die Tröpfchenübertragung ist eine Form der aerogenen Übertragung.
B Die Tröpfchenübertragung ist eine Form der direkten Kontaktübertragung.
C Die Tröpfchenübertragung ist eine Form der indirekten Kontaktübertragung.
D Die Tröpfchenübertragung ist eine Form der biologischen vektor-assoziierten Übertragung.
E Die Tröpfchenübertragung ist eine Form der Vehikel-assoziierten Übertragung
A Salmonella typhimurium
B Masernvirus
C Epstein-Barr-Virus
D Borrelia burgdorferi
E Vancomycin-resistente Enterokokken
A durch die Luft
B durch Tröpfchen
C durch direkten Kontakt
D durch indirekten Kontakt
E über Vektoren
A Clostridium difficile
B Staphylococcus aureus
C 4MRGN Klebsiella pneumoniae
D Rickettsia prowazekii
E Mycobacterium tuberculosis

A generelles Tragen einer FFP2-Maske

B generelles Tragen eines Mund-Nasen-Schutzes

C generelles Tragen von Schutzhandschuhen

D Händedesinfektion, richtiger Gebrauch der persönlichen Schutzausrüstung, MedizinprodukteAufbereitung und Reinigung der Patientenumgebung gemäß Regeln der Standard Precautions (Standard-/Basishygiene)

E Aufbereitung von Koloskopen, Steckbecken und Fieberthermometern gemäß Empfehlung der Kommission für Krankenhaushygiene und Infektionsprävention beim Robert-Koch-Institut und des Bundesinstitutes für Arzneimittel und Medizinprodukte 